\title{
ERRATUM
}

Tetsuya Ichikawa • Morihiro Aizaki • Mikio Takeshita

\section{Numerical study on amelioration of water quality in Lakes Shinji and Nakaumi: a coastal brackish lagoon system}

Published online: November 23, 2007

\section{Erratum to: Limnology (2007) \\ DOI 10.1007/s10201-007-0222-4}

We regret that the original version of this article contained an error. The presentation of Fig. 1 was incorrect. The figure is correctly shown here.

Fig. 1. Topography and location of the monitoring stations in Lakes Shinji and Nakaumi. regular monitoring stations of water quality; $\mathbf{a}$, monthly monitoring stations of water temperature and salinity (psu); $\mathbf{\Delta}$, Automatic Meteorological Data Acquisition System (AMeDAS) weather stations

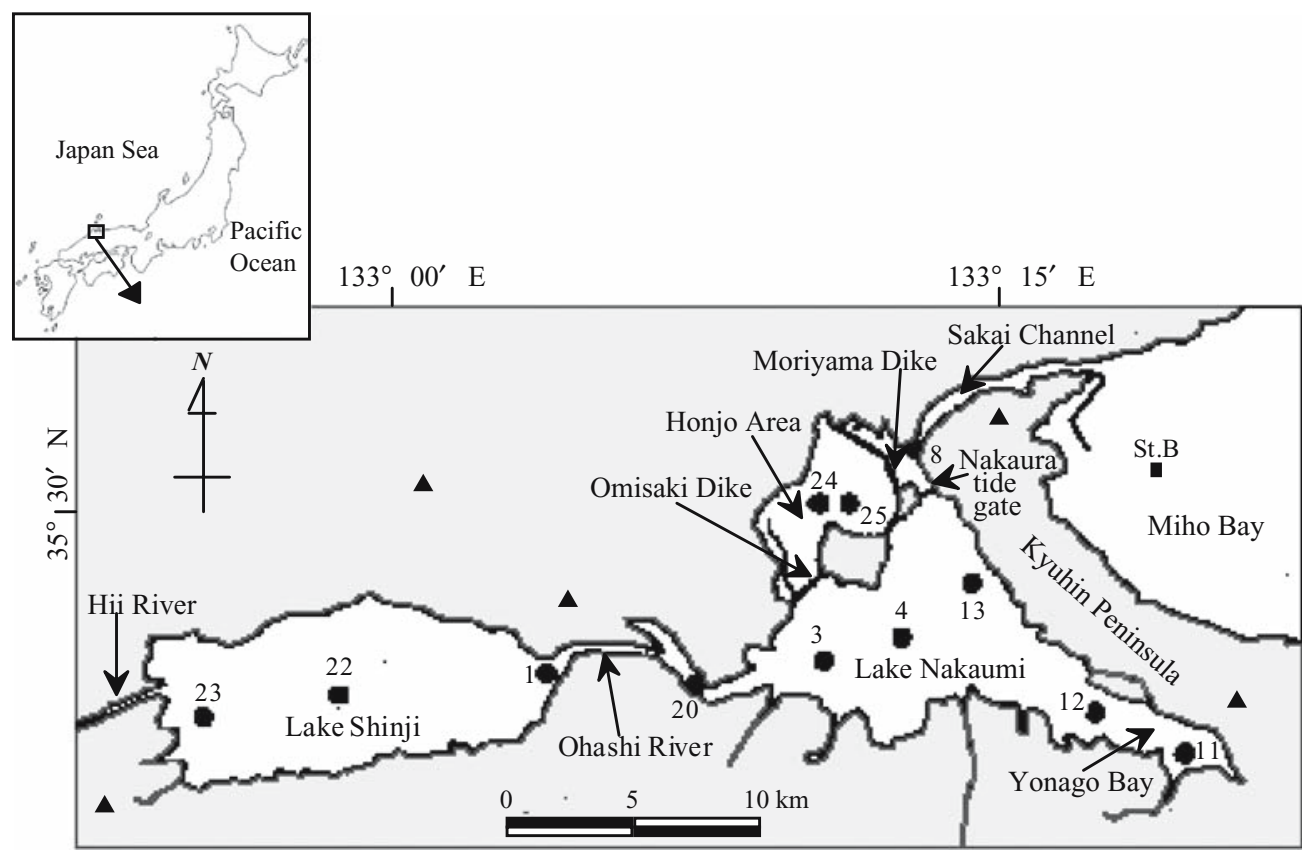

The online version of the original article can be found under doi: 10.1007/s10201-007-0222-4

\section{T. Ichikawa ${ }^{1}(\bowtie)$}

Environmental Information Department, Chuden CTI Co., Ltd.,

1-27-2 Meieki-Minami, Nakamura-ku, Nagoya 450-0003, Japan

M. Aizaki

Faculty of Life and Environmental Science, Shimane University, Shimane, Japan

M. Takeshita

Institute of Environmental Study on Brackish Lakes Shinji and

Nakaumi, Shimane, Japan
Present address:

${ }^{1}$ Science and Technology Co., Ltd., Nagoya Office, 2-14-1 Kanayama, Naka-ku, Nagoya 460-0022, Japan

Tel. +81-52-875-7233; Fax +81-52-875-7233

e-mail: tichikawa@sat-gis.co.jp 